\title{
A vaidade em Paul Rée: uma questão entre Nietzsche e Schopenhauer*
}

\author{
Vanity in Paul Rée: a question between Nietzsche and \\ Schopenhauer
}

\author{
Bruno Martins Machado \\ Doutor em Filosofia pela Unicamp \\ Professor do Departamento de Psicologia da Universidade Federal de Sergipe \\ E-mail: br.ma.machado@gmail.com
}

\begin{abstract}
Resumo: No presente artigo, através da noção de vaidade, apontamos uma ligação psicológica entre os conceitos de "vontade de vida" de Schopenhauer e de "vontade de poder" de Nietzsche. Percebe-se que tal vínculo foi esquecido pelos comentadores, pois a análise da noção de vaidade tanto em um filósofo quanto em outro não oferece todas as peças do quebra-cabeça. Aparentemente, falta algum termo. Nossa hipótese para superar tal lacuna é: faz-se necessário entender como Paul Rée desenvolveu em Observações psicológicas parâmetros filosóficos que permitiram o emprego da noção de vaidade na análise das ações humanas. Entendemos, portanto, que foi Rée quem forneceu os elementos com os quais Nietzsche pôde caminhar da noção de vaidade ao conceito de vontade de poder.
\end{abstract}

Palavras-chave: Schopenhauer; Rée; Nietzsche; Vaidade.

\begin{abstract}
In this paper I point out, by means of the notion of vanity, to a psychologycal connection between Shopenhauer's concept of 'will to live' and Nietzsche's 'will to power'. I consider that such an interpretative possibility has been forgot by the scholars due to the fact that the analysis of the notion of vanity, be it in relation to Schopenhauer's or Nietzsche's philosophy, does not provide us with all the elements of the puzze at hand. A term capable of conection both philosophies, regarding this issues, seems to be lacking. My hypothesis is that in order to achieve such a connection, it is necessary to understand how Paul Rée developed in Psychological Observations some philosophical parameters wich make it possible to use the concept of vanity to analyse humen actions. I understand, therefore, that it was Rée who furnished the elements by means of wich Nietzsche was able to, departing from the notion of vanity, achieve the concept of 'will to power'.
\end{abstract}

Keywords: Schopenhauer; Rée; Nietzsche; Vanity.

\footnotetext{
* O presente artigo é uma versão adaptada da minha conferência apresentada no VII Colóquio Internacional Schopenhauer, ocorrido na Universidade Federal da Bahia (UFBA), em Salvador, de 26 a 30 de outubro de 2015.
} 
$\mathrm{O}$ s elementos que aproximam ou distanciam a filosofia de Schopenhauer em relação à de Nietzsche são continuamente debatidos por comentadores e especialistas. Contudo, acredito que um momento específico da relação entre ambos ainda merece destaque. Esse período é marcado pela aproximação de Nietzsche a um outro schopenhaueriano, o doutor Paul Rée. No presente texto, através da noção de vaidade, proponho uma linha que se estende do conceito de vontade de vida ao conceito de vontade de poder, passando pela noção de vaidade.

Antes de iniciar, um breve esclarecimento. Muito provavelmente esta forma de abordar o problema foi esquecida porque a análise da noção de vaidade em Schopenhauer e em Nietzsche não nos oferece todas as peças do quebra-cabeças quando estudadas separadamente. É necessário entender o que é a vaidade para Paul Rée. É Rée quem fornece a interpretação positiva da vaidade associando-a à ambição através de elementos darwinistas. Tais construções foram absorvidas por Nietzsche como chave de compreensão do agir humano.

Como eixo estrutural de nossa argumentação, apoiamo-nos na ideia de que, apesar de já ter sido trabalhada por Schopenhauer em algumas obras como em Aforismos para sabedoria de vida, a vaidade, na forma como foi explorada por Paul Rée, forneceu substrato ao dinamismo da psicologia de Nietzsche. Sendo assim, no presente texto, seguiremos a seguinte ordem: Primeiro, apresentaremos como o conceito de vaidade em Schopenhauer seria uma forma mais exacerbada do egoísmo. Sendo assim, a vaidade exprimiria em sua essência o imperativo da vontade de vida. Depois, mostraremos como Paul Rée transforma a vaidade em um conceito psicológico de duplo caráter, um positivo e outro negativo. Para tanto, Rée se afasta de Schopenhauer e se apoia em elementos empíricos provenientes da fisiologia, da história e do naturalismo de acentuada tendência darwinista. Por fim, apontaremos em Humano demasiado Humano os termos segundo os quais Nietzsche (amplamente influenciado por Rée) alinha sua concepção de vaidade a uma base psicológica que implicará em sua obra de maturidade no conceito de vontade de poder. 


\section{Schopenhauer: a vaidade como auto-imagem de si}

No quarto livro de $O$ mundo como vontade e como representação, no capítulo 59 , Schopenhauer anuncia em termos gerais que retomará nas páginas seguintes a sua hipótese: "a vontade do homem é e permanece aquilo em relação a que, para ele, tudo depende"1. 0 fio condutor de sua linha argumentativa seguirá a ideia de que nos seres vivos a afirmação da vontade é a "afirmação da vontade de vida" 2 . No caso do homem, "a afirmação da vontade é o constante querer mesmo"3, que quando pensado como querer individual "é um outro modo de exposição da mesma coisa-em-si cujo fenômeno o corpo já é"4.

Nessa trama está em jogo o imperativo egoísta da vontade objetivada, que no homem manifesta sua natureza através do corpo. Dessa forma, Schopenhauer nos aproxima da ideia de que:

O tema fundamental de todos os diferentes atos da vontade é a satisfação das necessidades inseparáveis da existência do corpo em estado saudável, necessidades que já tem nele a sua expressão e podem ser reduzidas à conservação do indivíduo e à propagação da espécie ${ }^{5}$.

Uma das implicações provenientes de tal ponto de vista esbarra na pergunta: Como o homem, que é um animal dotado de intelecto, quer manter sua existência mesmo sabendo que o sofrimento está "enraizado na essência da vida"6?

Para solucionar tal problema, Schopenhauer recorre a uma espécie de artifício empreendido pelo intelecto. Um tipo de compensação que justificaria a existência mesmo diante do sofrimento. Indicamos aqui o primeiro termo de uma equação que responderia à pergunta formulada acima: Se "este mundo dos homens é o reino do acaso e do erro, que o governam sem piedade, tanto nas grandes quanto nas pequenas coisas, auxiliados pelo chicote da insensatez e da maldade" 7 , então, o intelecto elabora condições que nos motivam a continuar vivendo. Tais

\footnotetext{
${ }^{1}$ SCHOPENHAUER, A. WWV I / MVR I, § 59, p. 419.

2 Idem, § 60, p. 422.

${ }^{3}$ Idem, p. 420.

4 Ibidem.

5 Ibidem.

${ }^{6}$ Idem, § 59, p. 416.

${ }^{7}$ Idem, p. 417.
} 
condições são determinantes na justificação das representações que o homem faz do mundo. Em alguns casos, elas permanecem no limiar mais superficial da existência. Como atesta o filósofo: "De certo a vida humana, como qualquer mercadoria ruim, é coberta no exterior com um falso verniz; já o sofrimento todavia é sempre ocultado"8.

Especificamente, quero chamar atenção para o jogo instaurado por Schopenhauer. É uma dinâmica de apresentação de justificativas à representação que segue a seguinte orientação: "todos ostentam a pompa e o esplendor desfrutados; porém, quanto mais a satisfação interior lhes escapa tanto mais desejam apresentar-se como felizes na OPINIÃO DOS OUTROS"9. Se colocarmos esse termo junto ao outro, podemos dizer que um dos produtos do intelecto que motiva o homem a continuar vivendo ampara-se no que ele extraí da opinião de outros. Isto significa que em alguns casos, o homem oculta o sofrimento fundamental, cobrindo a sua vida com imagens que outros fazem dele. Desse modo, a solução para a pergunta acima se liga a um dos temas fundamentais encontrado em todo ato da vontade, a saber, a conservação. Em resumo, é possível dizer que o homem usa a tendência egoísta presente na natureza da vontade objetivada para justificar a existência através da apropriação da opinião de outros.

Notadamente, Schopenhauer é taxativo quanto ao papel negativo desse modo vazio de construir justificativas para a representação. Sobre aqueles que vivem de exaltar em si imagens provenientes da opinião dos outros ele escreve: “Tão longe vai o desvario. A opinião dos outros é o objetivo principal de cada um, embora a completa nulidade, vanitas, significa originariamente vazio e nulidade"10. A vaidade, portanto, forneceria justificativas para a existência através de um manejamento ao avesso de imagens criadas por outros.

Para corroborar nossa análise, podemos nos valer do texto Sobre orgulho e vaidade em Kant, Schopenhauer e Nietzsche, escrito por Müller-Lauter. 0 comentador atesta que, alinhado a Kant, Schopenhauer distinguiu de um lado o sentimento de honra (Ehrgefühl), o amor-próprio (Selbstliebe) e o orgulho (Stolz);

\footnotetext{
8 Ibidem.

${ }^{9}$ Idem, p. 418.

10 Ibidem.
} 
do outro lado, colocou a vaidade (Eitelkeit) ${ }^{11}$. A vaidade teria um sentido próximo aquele da soberba, termo que remete diretamente ao latim superbia e que denota um sentimento de satisfação proveniente da manifestação perversa de superioridade.

Contudo, apesar de concordarem sobre esse aspecto, Kant e Schopenhauer diferem diametralmente quanto ao funcionamento da vaidade no quadro do dinamismo ético humano. Segundo Müller-Lauter, a diferença se deve à "concepção de Schopenhauer de representação"12, que "em diferença à compreensão de Kant de aparência"13 propicia ao conceito de vaidade um sentido próprio.

Quando Kant fala da tolice da arrogância [Hochmütig], na verdade com isso ele destaca que se trata aqui de "vaidade no uso como meio para alguma coisa", isso não tem "valor" para poder ser efeito. Mas essa vaidade é aquela com sentido específico de modo de aparecer. Na verdade, ele pode escrever que segue na ambição tão somente o 'esforço para a fama pela honra, onde é suficiente parecer. Esse parecer é todavia para Kant aparência, que surge no comportamento para suporte moral do senso de honra; ela não é nada parecer no sentido de Schopenhauer ${ }^{14}$.

Acompanhando Müller-Lauter, o diferencial que se configura em Schopenhauer é conceber a vaidade como um valor. Um valor que se estabelece desde o início como um "verniz" posto sobre a vida. Mas que mesmo na superfície, é eficaz na análise dos comportamentos do homem. A vaidade estaria "profundamente enraizada na essência humana"15 por sua relação direta com o sofrimento e por sua relação com o egoísmo.

Na primeira relação, o vaidoso foge da ideia de encarar a vida como um fardo. Em resposta, ele cria imagens de si no intuito de receber elogios ou aprovações de outros. 0 prazer da sua existência proviria quase sempre dos elogios recebidos. A vida se torna um palco no qual o vaidoso entraria em cena para receber os aplausos pela sua atuação. Esse modelo, não toca o efetivo problema da existência e afasta o homem do conhecimento.

\footnotetext{
11 Cf. MÜLLER-LAUTER, W. Über Stolz uns Eitelkeit bei Kant, Schopenhauer und Nietzsche, p. 144.

12 Idem, p. 146.

13 Ibidem.

14 Idem, p. 147.

15 Idem, p. 148.
} 
Na segunda relação, como nossa natureza é para Schopenhauer egoísta, cada indivíduo faz

de si mesmo o centro do universo, antepondo a própria existência e o bem-estar a tudo o mais, sim, do ponto de vista natural está preparado a sacrificar qualquer coisa, até mesmo a aniquilar o mundo, simplesmente para conservar mais um pouco o próprio simesmo, esta gota no meio do oceano. Eis aí a mentalidade do EGOÍSMO, o qual é essência de toda natureza ${ }^{16}$.

Por isso, em alguns casos, o vaidoso não mede esforços para conseguir a admiração de outros. Lembremos que o que vale na vaidade é o desejo de apresentar-se feliz na opinião dos outros. Assim, o vaidoso forja imagens para ser admiradas pelos outros e tenta mantê-las a todo custo. A satisfação com tal conduta, não se resume unicamente a um modo de representar a si mesmo. Portanto, é um traço que envolve um aspecto psicológico do homem. A constituição psicológica da vaidade foge ao conteúdo de $O$ mundo como vontade e como representação. Ela é explorada em outra obra, Aforismos para a sabedoria de vida.

Nos Aforismos, uma espécie de tratado eudemonológico ${ }^{17}$, Schopenhauer vincula a vaidade ao conceito de felicidade e à moral. É o aprofundamento da relação da vaidade com a natureza egoísta do homem, tratada primordialmente a partir do ponto de vista psicológico. Nesse sentido, as discussões sobre vaidade são continuamente relacionadas com as motivações e com os comportamentos.

Segundo Schopenhauer, o caminho para a felicidade é orientado por três "rubricas". Elas norteiam o comportamento dos homens interessados nos bens da vida. A primeira rubrica seria "aquilo que somos", a segunda "aquilo que se tem" e a terceira "aquilo que se representa". "O primordial e mais essencial é aquilo que somos, nossa personalidade, porque ela é constante e ativa em todas as circunstâncias"18. Em segundo lugar, vem aquilo que se tem, que obedece a uma hierarquia das "necessidades humanas"19. Decorre daí que, por ordem de satisfação, as mais importantes são as necessidades naturais e necessárias, depois

\footnotetext{
16 SCHOPENHAUER, A. WWV I / MVR I, § 61, p. 426-427.

17 SCHOPENHAUER, A. P/P. Aforismos para a sabedoria de vida, p. 01.

18 Idem, p. 07.

19 Idem, p. 49.
} 
as necessidades naturais e não necessárias e, por fim, as necessidades não naturais e não necessárias.

A terceira rubrica é aquela que interessa mais em nosso percurso. Ela tem como base a satisfação a partir da "nossa existência na opinião dos outros" 20 . Especificamente, sob tais parâmetros "compreende-se o que alguém é na representação dos outros, portanto, propriamente como vem a ser representado por eles"21. Schopenhauer divide essa representação em três tipos: "honra, posição e glória"22.

Mesmo aparentando uma contradição, pois "em si mesma, tal coisa [a opinião dos outros] não é essencial para a nossa felicidade"23, Schopenhauer a considera importante na busca pela felicidade. A justificativa para tanto é estritamente de natureza psicológica, pois "se tal característica serve de base para o sentimento de honra, ela pode gerar efeitos salutares sobre a boa conduta de muitos, enquanto sucedâneo para sua moralidade"24. Mas, se tomada em uma outra direção, ela pode se tornar prejudicial basta que "a imagem do seu ser na cabeça dos outros" seja "mais importante do que este próprio ser (...) tal valoração imediata do que para nós não existe constitui aquela insensatez que se denominou vaidade, vanitas"25. Conclui-se, então, que para Schopenhauer a área de aparição da vaidade gira em torno da cobiça por honra.

Em uma formulação psicológica tem-se que: quando nossa auto-imagem é acariciada pela opinião de outro, nossa "vaidade é de algum modo adulada" 26 . Assim, para garantir a permanência de uma determinada imagem criada, em muitos casos o homem se comporta de modo a fortalecê-la cada vez mais. Neste sentido, o vaidoso se prende continuamente ao exercício de representação de si, afastando-se do desapego necessário ao agir ético. Seu espaço psicológico infla-se cada vez mais com auto-representações, tornando-se difícil encontrar caminhos para ações compassivas. Quando se chega a tal ponto percebe-se, como atesta

\footnotetext{
${ }^{20}$ Idem, p. 61.

21 Ibidem.

22 Ibidem.

23 Ibidem.

${ }^{24}$ Idem, p. 61-62.

25 Idem, p. 66.

${ }^{26}$ Idem, p. 61.
} 
Schopenhauer, que "a vaidade, assim como a avareza, pertence ao esquecimento dos fins pelos meios"27.

Apesar de problemática, essa forma de prazer consigo proporcionada pela vaidade orienta repetidamente o comportamento humano. Curioso é observar, como aponta Schopenhauer, que tanto o nobre quanto o vil, tanto o grande quanto o pequeno - todos querem mostrar o que de si é o melhor, ou seja, há em geral a preocupação com a manutenção da autoimagem. E assim, sobre a construção da auto-imagem e sobre a execução de papéis para manter tal imagem perante os outros, Schopenhauer, em plena concordância com o Eclesiastes, indica: "Tudo é vaidade".

\section{Rée: a vaidade como motivação positiva}

Em Observações Psicológicas ${ }^{28}$, Paul Rée apresenta algumas análises baseadas no agir humano. Como se sabe, o livro inicia com uma citação extraída de Gobineu: "o homem é um animal malvado por excelência"29. Um extrato cuja referência está também em Parerga e Paralipomena. Essa pequena frase já indica a forte influência schopenhaueriana no conjunto das teses apresentadas por Rée. Como escreve Domenico Fazio: "as Observações psicológicas estão completamente imersas em um pessimismo frio e sóbrio: o homem é o animal malvado por excelência e seu procedimento é cunhado sempre pelo egoísmo, conformismo, inveja e vaidade" 30 .

Contudo a particular composição do pessimismo de Rée esquiva-se em parte daquele apresentado pelo seu mestre. Enquanto Schopenhauer se apoia no egoísmo, na maldade e na compaixão para estabelecer uma distinção entre os tipos de caráter do homem, tomando as ações morais a partir da ausência de motivação egoísta ${ }^{31}$, Rée procura analisar a conduta humana sem prender a efetividade às

\footnotetext{
27 Idem, p. 66.

${ }^{28}$ Cf. RÉE, P. Psychologische Beobachtungen, pp. 59-125. Doravante, para as citações desta obra utilizaremos os mesmos critérios adotados para Schopenhauer: sigla do nome da obra em alemão / português (PB / OP), número do aforismo ou nome do trecho, número da página.

${ }^{29}$ RÉE, P. PB / OP, p. 59.

${ }^{30}$ FAZIO, D. Paul Rée. Philosoph, Arzt, Philanthrop, p. 59.

${ }^{31} \mathrm{Cf}$. SCHOPENHAUER, A. M/M.
} 
"cegas e irracionais configurações de poder como essência nomênica"32.

Em última instância, o que está em questão no livro é a reflexão sobre as ações e suas causas. Assim, é possível dizer que o suporte para os aforismos de Observações Psicológicas ergue-se sobre a tese de que "toda ação se apoia em um mosaico de motivos [Mosaik von Motiven], sem que nós sejamos capazes de reconhecer o quanto de egoísmo, vaidade, orgulho, medo, benevolência etc. ela é composta"33. Essa ideia fundamental dá o tom da obra.

Dentre tantas possibilidades de motivos para os comportamentos, Rée atribui um peso especial à vaidade. Em Observações Psicológicas o termo aparece 53 vezes. 0 conceito consta no livro sob o índice de uma aparente flutuação. Contudo, sua dispersão não é fortuita, seu emprego se mantém atrelado a explicações sobre os motivos que fundamentam as ações humanas. Quase todas as sensações que eliciam uma ação podem ser deduzidas a partir da vaidade. Rée deixa essa perspectiva bem clara quando, por exemplo, no aforismo 132 trata da inveja. Para ele, "a maioria das sensações de inveja não derivam do interesse próprio, mas sim da vaidade"34. A vaidade surge como um elemento psicológico que agrega sensações em torno de um objeto específico. Ela tem sua amplitude estabelecida não apenas no âmbito individual mas também no dinamismo das relações sociais.

Durante boa parte do livro de 1875, o modo como Rée trata a vaidade leva o leitor a uma compreensão geral do conceito. 0 filósofo apresenta sua aplicação e funcionamento através de exemplos que envolvem o dinamismo das emoções e sensações do homem. Ao fim do penúltimo capítulo do livro, sabe-se que a vaidade é muito importante, porém fazem falta alguns parâmetros explicativos.

Para dar conta dessa lacuna, no último capítulo, Ensaio sobre a vaidade [Versuch über die Eitelkeit], uma espécie de apêndice inteiramente dedicado ao tema, o leitor encontra algumas especificações teóricas que denotam efetivamente a importância do conceito na filosofia de Rée. Devemos lembrar que estruturalmente essa parte se diferencia completamente das outras. Não tem mais o formato de um aforismo. É um pequeno ensaio dissertativo, subdividido em três partes. Em todos os trechos percebe-se uma declarada proximidade ao

32 FAZIO, D. Op. cit., p. 59.

${ }^{33}$ RÉE, P. OP / PB, § 46, p. 65.

${ }^{34}$ Idem, $\S 132$, p. 76. 
darwinismo, o que confere ao texto um tom de escrito científico.

Na primeira sub-parte, Rée se preocupa em mostrar que a opinião que os outros fazem de alguém são relevantes no modo como as pessoas se comportam. Isso acontece porque tais opiniões podem causar prazer ou desprazer. Ele escreve: "É por duas razões que os homens não são indiferentes"35. A primeira razão é porque as pessoas agem por "interesse próprio"36, ou seja, elas esperam vantagens "de uma boa opinião"37. A segunda razão é porque as pessoas são vaidosas, isto é, receber uma boa opinião é prazeroso para quem é elogiado. Sob tal determinação, Rée divide a vaidade em positiva e negativa. "Esta vaidade positiva se divide em vaidade em sentido estrito e ambição. (...). 0 lado negativo da vaidade (em virtude do qual é doloroso por tornar-se pouco estimado e desprezado) designa o uso comum da linguagem [Sprachgebrauch] como sentimento de honra"38.

Essa classificação como positiva ou negativa abre espaço para Rée aprofundar a noção de vaidade como valor. Em si a vaidade não é um motivo. Ela não é um sentimento ou uma sensação, ela é um produto psicológico. Por essa razão Rée é taxativo ao afirmar que: “Em vez de 'ele é orgulhoso, egoísta' deveria dizer mais precisamente: 'Vê-se seu orgulho, seu egoísmo e sua vaidade'”39. Se tomarmos a tristeza por exemplo, o homem que sofreu uma intempérie na vida se sente triste por causa de um acontecimento. A relação de causalidade é direta: um infortúnio causa tristeza. Por sua vez, o vaidoso não sente a vaidade, ele sente prazer por conseguir alcançar um determinado significado segundo a opinião de alguém. A vaidade denota a condição psicológica a qual o indivíduo está submetido: “as expressões 'egoísmo', 'vaidade' etc. não correspondem de forma alguma aos sentimentos os quais eles designam: eles são, com efeito, apenas dedos indicadores [Fingerzeige]" 40 .

Nesses termos, percebe-se que também para Rée o conceito de vaidade assume o estatuto de valor. Não se pode negar a influência de Schopenhauer quanto a esse aspecto. A diferença entre ambos é que na filosofia de Rée o espaço

\footnotetext{
35 RÉE, P. OP / PB, Vaidade / Eitelkeit, p. 121.

36 Ibidem.

37 Ibidem.

38 Ibidem.

${ }^{39}$ Idem, § 91, p. 71.

40 Idem, $§ 46$, p. 65.
} 
de atuação da psicologia é ampliado, permitindo que os valores possam ser considerados como produtos empíricos. Acreditamos que por causa dessa variação de registro desenvolvem-se grandes consequências. Nietzsche foi capaz levar ao extremo o alcance de tal mudança de registro como veremos no próximo tópico.

0 alcance dessa mudança de registro fica mais evidente na segunda subparte do capítulo. Nela Rée apresenta sua dedução empírica do dinamismo psicológico da vaidade. Ele demonstra que a concepção de um fenômeno como valor também deve ter sua origem extraída de ordens de eventos naturais. De declarada influência darwinista, o trecho reconstrói a imagem de um passado que corresponde "aos primeiros níveis da civilização"41. 0 ponto de partida é a problematização dos fundamentos da vaidade, a saber, o prazer e o desprazer provenientes de ser ou não admirado. A questão é: "por que agradar e ser admirado em si e por si são prazerosos e por que ser pouco valoroso e ser menosprezado em si e por si são dolorosos, é obscuro" 42 ?

Alegar falta de clareza tem uma explicação. 0 percurso histórico dos acontecimentos não é exato e linear. Ele se perde com o passar do tempo. Eventos que aconteceram na pré-história do homem não são lembrados em sua totalidade, muitas vezes caem em esquecimento. Rée procede tal como o geólogo, busca compor um quebra-cabeças com as peças que ainda lhe restam. Um processo de construção e reconstrução concebido eminentemente através de experimentos hipotéticos. Assim foi possível remontar as condições gerais que colocam a vaidade no cerne da dinâmica psicológica do homem.

Rée parte da ideia de que "os primeiros homens, que viviam uns com os outros em hordas, não possuíam vaidade"43. Estes homens na disputa pelas fêmeas do grupo, começaram a fazer coisas que despertavam a atenção das mulheres. Nesse ponto, Rée indica que a consistência científica dessa tese já foi provada por Darwin. Logo, como um homem de ciência, ele irá segui-la de perto. Voltando ao texto, Rée pergunta o que poderia chamar a atenção das mulheres? Construir ferramentas. Por exemplo, armas que fossem admiradas por todos, isso poderia ser importante para um homem conquistar posição e visibilidade.

Em tempos de guerra, a boa arma teria função imprescindível para a

\footnotetext{
${ }^{41}$ Idem, Vaidade / Eitelkeit, p. 121.

42 Ibidem.

43 Ibidem.
} 
sobrevivência do indivíduo e de sua tribo. As armas produzidas por uma determinada pessoa teriam assim um alto valor de troca diante de outras mercadorias. 0 artesão que a produzisse conquistaria assim a admiração dos outros. Para conseguir a generalização da sua hipótese, Rée se valeu também da influência dos utilitaristas ingleses. Ele acrescentou que por força do habito, mesmo em momentos de paz o valor agregado à arma poderia ser mantido. Portanto, a posição de destaque do artesão também estaria garantida. “Com isso se deu o primeiro passo para a vaidade" 44 .

O segundo passo também é um outro argumento evolucionista, mas não mais darwinista. Segundo Rée, acontece que com o passar do tempo:

O instinto ou a pulsão assim adquirido é então herdado pelos descendentes e seu uso permanente através de muitas gerações possibilitou ser fixado. Finalmente, através da seleção natural, quer dizer através de extraordinário fortalecimento, a vaidade teve que vir a ser, que na luta pela existência permaneceram aqueles tribos [Stämme] remanescentes, os quais continham um maior número de homens vaidosos ${ }^{45}$.

A vaidade torna-se, então, um dos motivos mais contundentes do agir humano. Seguindo proposições naturalistas sobre a vaidade, Rée delineou o dinamismo psicológico sobre a aquisição e atribuição de valor. Estaria explicado o porquê do homem, usando sua capacidade de representar a si mesmo, concebeu esquemas de satisfação de impulsos não mais ligados unicamente à ordem fisiológica da liberação da descarga. Uma aparente contradição havia sido justificada: alguém poderia sentir prazer ao ter algo de si elogiado por outros mesmo que no momento estivesse passando por um momento doloroso.

Significa dizer que a vaidade explica a conexão entre uma ação e um outro motivo que não aparece no âmbito mais superficial do acontecimento ${ }^{46}$. Consequentemente, a satisfação de um desejo pode ter uma motivação oculta, distinta daquela mais aparente ${ }^{47}$. Isso significa que, em Observações psicológicas,

\footnotetext{
44 Idem, p. 122.

45 Ibidem.

46 FAZIO, D. Op. cit., p. 81.

47 Sob tais determinações, a consciência ou o ego se tornaria a estrutura mais superficial do nosso psiquismo. As realizações e satisfação dos desejos conscientes não implicariam na satisfação do homem.
} 
Rée aprofundou a explicação psicológica que liga uma ação à consciência dos propósitos de sua execução, ou seja, foi possível colocar o agir como um elemento proveniente de uma sensação aparentemente secundária, mas que na representação que alguém faz de si mesmo, toma a frente das outras representações. Essa tese de traços schopenhauerianos mantém o jogo entre apresentar e representar. Entretanto, ela abre espaço para que se encontre na constituição da imagem de si justificativas inconscientes próprias ao dinamismo psicológico de cada um.

É importante ainda voltarmos a um pouco atenção a um outro aspecto darwinista presente no pensamento de Rée. Quando esse caracteriza a vaidade positiva de acordo com duas determinações, vaidade em sentido restrito e em ambição, ele altera também o funcionamento psicológico que orienta a satisfação dos impulsos:

\begin{abstract}
Vaidade positiva pode ser dividida em vaidade em um sentido mais restrito e em ambição. É uma característica da pessoa que é vaidosa, no sentido mais restrito, que está satisfeita com a quantidade de admiração e inveja que ela goza no momento, enquanto que, a pessoa ambiciosa não está satisfeita com isso: a última quer conseguir mais admiração - se possível, ser mais admirado e invejado do que qualquer outro 48 .
\end{abstract}

A linha divisora das duas especificações acima se forma sobre a direção para onde se volta o prazer. Torna-se evidente que o prazer do vaidoso provém: (i) da sensação de satisfação por conseguir realizar um feito, ou seja, satisfação por saciar o desejo de ter sua auto-imagem admirada; (ii) da sensação de satisfação pela afirmação de um estado de superioridade, isto é, a auto-imagem não apenas foi admirada por outros, mas também foi admirada mais do que qualquer outra de qualquer outro homem. Para justificar essa segunda determinação, Rée especifica o que moveria alguém a querer ser admirado mais do que todos os outros: "Todo homem encontra-se como que em uma corrida com outros: ele quer agradar mais, ser admirado mais, ser invejado mais que os outros e uma alegria maligna [Schadenfreude] deriva do sentimento que os outros são inferiores a nós ou

${ }^{48}$ RÉE, P. OP / PB, Vaidade / Eitelkeit, p. 123. 
respectivamente não são superiores a nós"49.

A sensação de prazer conseguida ao atingir tal estado superior efetiva-se como uma das mais fortes motivações no homem ${ }^{50}$. Em última instância, Rée promove através da vaidade o aprofundamento dos fundamentos e da dinâmica psicológica das motivações humanas. Mantendo a tese schopenhaueriana de que "tudo é vaidade", ele consolida a noção de vaidade como um valor em torno do qual orbitam outros valores. Um valor que tem um dinamismo específico seja (i) por associar psicologicamente a representação à descarga de prazer, psicologizando a formação de representações; seja (ii) por subordinar a descarga de prazer à ambição - em busca de prazer o homem sempre quer mais e quer ir além. 0 propósito da existência não se limita a manter a vida.

\section{Nietzsche: da vaidade ao sentimento de poder}

Em Humano demasiado Humano ${ }^{51}$, no aforismo 89, Nietzsche traçou o que seriam determinações gerais para o conceito de vaidade. Ele escreveu:

Cuidamos da boa opinião das pessoas, primeiro porque ela nos é útil, depois porque queremos lhes dar contentamento (...). Apenas quando alguém acha importante a boa opinião alheia sem considerar o proveito ou o desejo de contentar é que falamos de vaidade. Nesse caso, o indivíduo quer contentar a si mesmo, mas à custa de seus semelhantes, induzindo-os a uma falsa opinião a seu

\footnotetext{
${ }^{49}$ Ibidem. 0 trecho citado corresponde integralmente à única nota de Observações psicológicas, presente em Ensaio sobre a vaidade. Percebemos que Rée apresenta a busca pela superação dos indivíduos da espécie como um desdobramento natural e evolutivo do impulso pela sobrevivência. Se Nietzsche pode ser acusado de corrigir a vontade de vida schopenhaueriana, estabelecendo no seu lugar a vontade de poder, esse seria o trecho que fundamenta tal justificação. Uma observação de caraterísticas empíricas e que foi assimilada ao seu pensamento desde Humano demasiado Humano.

${ }^{50}$ A busca pelo prazer não depende da consciência, mas, ao reconhecer a motivação mais intensa que guia alguém, a consciência pode auxiliar um homem a atingir um almejado estado de satisfação. Essa tese se mantém em Nietzsche: "Na natureza obtemos prazer quebrando galhos, removendo pedras, lutando contra animais selvagens, para nos tornarmos conscientes de nossas forças" (NIETZSCHE, F. HH / MA, § 103, p. 78).

${ }^{51}$ Para Nietzsche, utilizaremos os mesmos critérios adotados para Schopenhauer e Rée: sigla do nome da obra em alemão / português (HH / MA), número do aforismo ou nome do trecho, número da página. Ainda sobre as obras de Nietzsche, pelo maior alcance optamos por utilizar preferencialmente as traduções para o português de Paulo César de Souza e de Rubens Rodrigues Torres Filho. Mas, quando julgamos que a versão do intérprete se afastava da original, realizamos alterações pontuais ou traduzimos direto do original.
} 
respeito ou visando um grau de "boa opinião" em que esta vem a ser penosa para todos os demais (ao suscitar a inveja) ${ }^{52}$.

Como vimos até agora, em Schopenhauer, em Rée a vaidade envolve a construção de uma representação de si. Nietzsche, por sua vez, segue a mesma determinação. Para ele a vaidade reflete a busca pela aprovação de uma imagem que um homem produz de si mesmo. A primeira diferença entre os três surge quando Schopenhauer atribui uma conotação negativa a estima por essa imagem. Assim, a vaidade emerge como uma espécie de modalização psicológica negativa do egoísmo. Como vimos anteriormente, em $O$ mundo como vontade e como representação, a vaidade aponta para uma busca que se orienta pelo nada. Ela sinaliza um lugar vazio que não deve ser tomado como o impulso para as ações humanas. É por isso que a vaidade não pode funcionar como fundamento para a vontade de vida.

Em Rée, a vaidade pode adquirir conotações positiva ou negativa. Portanto, em sua raiz, ela permite a possibilidade de existência de forças psicológicas antagônicas agindo sobre as mesmas motivações. Quando gera prazer ela é positiva, quando gera desprazer é negativa. Então, uma mesma imagem de si, em um dado momento, pode gerar prazer e, em outro momento, poder gerar desprazer. Aquilo que diferencia os dois termos da vaidade (positivo e negativo) são os sentimentos e as sensações que ela desperta. É importante destacar que a vaidade na filosofia de Rée não possui uma forma delimitada, somente seu dinamismo no psiquismo humano é observável. Enquanto mecanismo psicológico, ela serve à multiplicidade de motivos que possam levar ao prazer.

Apesar de sua interpretação sobre a vaidade ser muito próxima da conotação positiva apresentada por Rée, Nietzsche elabora sua própria leitura. Seu modo de tratar o conceito é caracterizado pelos comentadores como uma especificidade de sua filosofia. Müller-Lauter defende que "como a representação para Nietzsche não envolve uma coisa-em-si, de modo diferente como seria em Kant e Schopenhauer, cai definitivamente em seu mundo do vir-a-ser a diferença entre ser e aparência, assim pode de fato a vaidade vir a ter um sentido positivo, como aliás o orgulho" 53 .

${ }^{52}$ NIETZSCHE, F. HH / MA, § 89, p. 68-69.

53 MÜLLER-LAUTER, W. Op. cit., p. 152. 
Em Nietzsche, a vaidade se liga à efetividade através do prazer. Entendemos que o filósofo se vale da determinação positiva atribuída por Rée ao conceito quando este foi classificado como "vaidade propriamente dita" e "ambição". Assim, há dois aspectos que garantem a positividade da vaidade. 0 primeiro provém da sensação de prazer que surge da aprovação da auto-imagem pela opinião dos outros. O segundo provém da sensação de prazer por usufruir da satisfação de conseguir impor cada vez sua auto-imagem. Desse modo, Nietzsche também leva ao extremo a tese schopenhaueriana de que "tudo é vaidade". Lemos no aforismo 12 de $O$ andarilho e sua sombra: "Vanitas vanitatum homo" [vaidade das vaidades é o homem $]^{54}$.

Se observarmos o contínuo aprofundamento psicológico no qual Nietzsche insere a vaidade, não é difícil vislumbrarmos que ela forneceu os elementos para a posterior elaboração do conceito de vontade de poder. Nos aforismos de Humano demasiado Humano I e Humano Demasiado Humano II é possível fazer o mapeamento dos termos que comprovam essa hipótese.

Em suas considerações sobre as ações do homem, Nietzsche identifica que um dos principais elementos por trás de nossos comportamentos provém do medo de não ter a imagem de si valorizada. Em Humano a busca por prazer toma a frente como justificativa fisiológica para os comportamentos. No livro de 1878, a possibilidade do outro não valorar nada em nós ou depreciar algo em nós pode abalar muito a imagem que alguém faz de si. Nesse caso, ao invés do prazer com a opinião do outro, experimenta-se o desprazer da reprovação. 0 sentimento que brota dessa expectativa de aprovação é o medo. Medo do outro receber de forma negativa a auto-imagem que um indivíduo faz de si. No fragmento póstumo 23[63] de 1876, Nietzsche distingue o medo como sensação negativa e o sentimento de poder como sensação positiva. O medo é identificado por Nietzsche como um impedimento para que se consiga enaltecer algo de si. Ele impede o impulso em direção à fruição de si [Selbstgenuß]. Nasce assim a primeira determinação psicológica efetiva do conceito de vontade de poder. Ela surge em contra-posição

${ }^{54}$ NIETZSCHE, F. AS / WS, § 12, p. 171. 
ao medo de não sentir o "sentimento de poder", advindo da fruição de si $[\text { Selbstgenu } \beta]^{55}$.

Temos, então, em uma mesma linha:

(i) a vaidade - que desemboca no prazer com a aprovação da autoimagem de si.

(ii) a vaidade - que surge do prazer pela fruição de si [Selbstgenuß], ou seja, por conquistar a boa opinião com a imagem.

(iii) o medo - que surge pela antecipação da possibilidade de não sentir a sensação de fruição de si, em outros termos, medo de perder o sentimento de poder gerado com as conquistas (esse termo foi caracterizado por Nietzsche como negativo).

Portanto, via sensação de prazer consigo trazida pelo "aumento na crença do poder"56, o filósofo uniu as caracterizações da vaidade em torno de em um só termo. Este será explorado em obras posteriores como sentimento de poder até chegar à formulação vontade de poder. Poderíamos nos perguntar se diante da abrangência da vaidade configurada por Nietzsche, ela seria a "coisa-em-si humana"57?

Ela seria o fundamento último sobre o qual se erguem todas as outras motivações. Mas com uma ressalva: apenas enquanto "termo genérico" 58 . Como anotou Nietzsche, a vaidade seria "uma das coisas mais plenas e ricas de conteúdo"59 e também "uma expressão que designa o mesmo que o verdadeiramente vazio e nulo"60. Sem uma materialização específica, a vaidade teria como determinação última o ímpeto de buscar mais prazer, sempre ir além através do auto-representação de si. Assim sendo, a vaidade apontaria para um lugar, o caminho constante da busca por "prazer consigo". Tal indicação caracteriza permanentemente o curso da vaidade como um sintoma das determinações ocultas de habitam em cada homem. Como defende Volker Gerhardt, nesse período Nietzsche segue uma determinação clara: “0 que ele procura é uma força pulsional

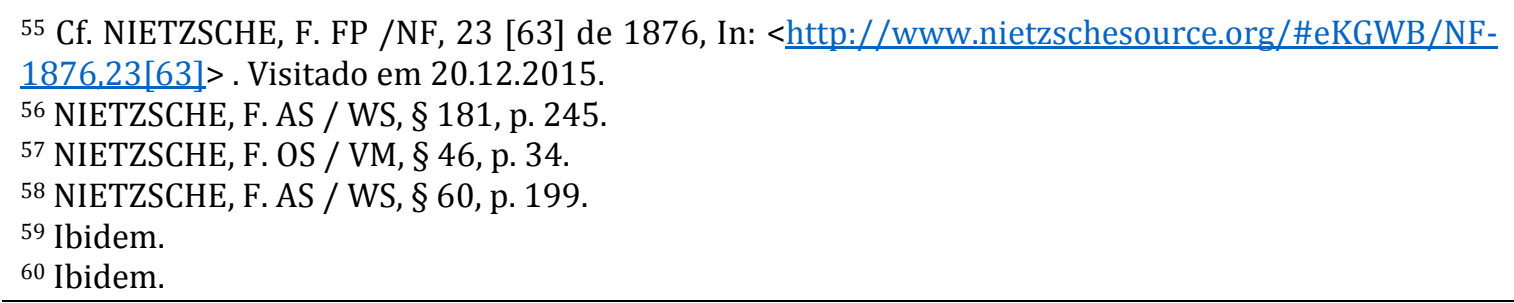


[Triebkraft], que sirva de base para todos os comportamentos e que por esse motivo também brote nas ações morais. Sua atenção se dirige de início ao papel central da vaidade" 61 .

No âmbito geral das motivações humanas, Nietzsche alerta: "Como seria pobre o espírito humano sem a vaidade!"62. "A vaidade enriquece"63, ou seja, ela não limita a ação do homem. Como pontuou Nietzsche, "a coisa mais vulnerável e, no entanto, a mais invencível é a vaidade humana: sua força até aumenta com o ferimento, e pode enfim tornar-se gigantesca"64. Esse extrato alerta para o impulso em ir além. Uma força que está ligada "à vontade e à capacidade de superar os outros" [Andere zu übertreffen $]^{65}$. Bastante próximo ao darwinismo de Rée, Nietzsche fornece assim a determinação última com a qual busca se satisfazer: "superar os outros". Temos, pois, duas determinações próprias à noção de vaidade que posteriormente nos escritos nietzscheanos de maturidade também estão presentes no conceito de vontade de poder: (i) busca pela realização e intensificação do sentimento de fruição de si - a sensação ser capaz de agir de uma determinada maneira ; (ii) busca pela superação - a sensação conseguir colocar-se para além de um limite.

\section{Considerações finais}

Em Humano demasiado Humano, a vaidade não é sinônimo de egoísmo. Logo, se há um "elemento básico"66, volátil, que "somente se revela na observação mais aguda"67, esse termo não é especificamente o egoísmo. Ele seria o prazer consigo mesmo proveniente da generalização da sensação trazida pela vaidade, ou seja, a fruição de si [Selbstgenuß]. Mas o prazer consigo mesmo não tem uma forma ou um endereço específico no corpo do homem. Assim, quando o investigador pergunta à vaidade pelo prazer do homem, esta responde primeiramente com uma representação. Tal impressão é aquilo que precisa da aprovação da opinião dos

\footnotetext{
${ }^{61}$ GEHARDT, V. Friedrich Nietzsche, p. 130.

${ }^{62}$ NIETZSCHE, F. HH / MA, § 79, p. 66.

63 Ibidem.

${ }^{64}$ NIETZSCHE, F. OS / VM, § 46, p. 34.

${ }^{65}$ RÉE, P. OP / PB, § Vaidade / Eitelkeit, p. 124.

${ }^{66}$ NIETZSCHE, F. HH / MA, § 01, p. 15.

67 Ibidem.
} 
outros para gerar uma sensação de prazer. A alteração que Nietzsche impõe a Schopenhauer é a radicalização do egoísmo como epicentro de todas as motivações humanas, ausentando-o das justificações metafísicas e tratando-o como um termo que expressa um efeito psicológico. Através da vaidade, a sensação de prazer proveniente da fruição de si e da superação se estende a todas ações. Nesses termos, não existe nenhuma substância metafísica que corresponda ao "em si" do egoísmo. Ele não reflete mais a vontade de vida. Sua imagem espelha a ambição tal como foi descrita por Paul Rée. Sem forma fixa ou identidade, ela apenas empurra o homem a um determinado caminho: a busca por prazer e pela sua intensificação.

Se considerarmos que desde Rée a vaidade pode tomar formas diversas, então, podemos entender que ela não se prende a uma motivação específica. Para Müller-Lauter, Nietzsche assumiu em parte a condição da vaidade de Schopenhauer concebendo-a como um valor, porém aproximou-se de Kant quando mais uma vez alinhou-a a uma sensação que retrataria uma espécie de "extravagância da altivez"68. As análises do comentador são justas, contudo, pelo que vimos até aqui, elas podem se aplicar inteiramente a Paul Rée. Isso ocorre porque já em Rée as motivações do homem são múltiplas, consequentemente, a vida não é exclusivamente sinônimo de conservação. Como vimos, nos seus escritos, a luta pela existência já sofre a marca do darwinismo. Assim, a vaidade já ganha maior amplitude - ela muda, especializa-se, pode assumir a marca da ambição.

Com tais afirmações, não quero reduzir a filosofia nietzscheana ao "réealismo". Contudo, quero evidenciar o significante papel de Paul Rée na construção do pensamento de Nietzsche. Curiosamente, em seus comentários à filosofia nietzscheana, Volker Gerhard passa por cima desse ponto. 0 comentador chega a apontar que existe a ligação entre a noção de vaidade e o conceito de vontade de poder: “Já em 'Humano demasiado Humano', há uma forte impressão, que se faz repentina e conhecida, que o inicial conceito fundamental de 'vaidade' se liga com o conceito tardio de 'vontade de poder'"69. Mas, por não se aprofundar na filosofia de Rée o problema do surgimento da vaidade parece brotar exclusivamente a partir de Nietzsche como "uma forte impressão, que se faz 
repentina e conhecida". Gehardt sinaliza, portanto, um estranhamento. Uma espécie de espanto com um conceito importante que surge aparentemente de uma hora para outra - há uma grande distância entre o conceito de vaidade em Schopenhauer e em Nietzsche.

Seguindo uma determinação dos gregos antigos, com o espanto começa a filosofia. 0 estranhamento sinalizado pelo comentador indica um efetivo problema: a genealogia da noção de vaidade e suas implicações na construção do conceito de vontade de poder. Acredito que o percurso indicado no presente texto aponta para uma solução: Schopenhauer é o grande interlocutor de Nietzsche, mas foi Paul Rée quem lhe deu ferramentas para alcançar sua independência filosófica.

\section{Referências bibliográficas}

FAZIO, Domenico. Paul Rée. Philosoph, Arzt, Philanthrop. München: Martin Meidenbauer, 2005.

GEHARDT, Volker. Friedrich Nietzsche. München: Verlag C.H. Beck, 2006.

MÜLLER-LAUTER, Wolfgang. Über Stolz uns Eitelkeit bei Kant, Schopenhauer und Nietzsche. In: Über Werden und Wille zur Macht. Berlin; New York: Walter de Gruyter, 1999.

NIETZSCHE, Friedrich. Digitale Kritische Gesamtausgabe. Hrsg. Giorgio Colli und Mazzino Montinari. In: www.nietzschesource.org/eKGB/. Visitado em 20.12.2015.

. Humano demasiado Humano. Trad. Paulo César de Souza. São Paulo: Companhia das Letras, 2000. (HH / MA).

O Andarilho e sua Sombra. In: Humano demasiado Humano II. Trad. Paulo César de Souza. São Paulo: Companhia das Letras, 2008. (AS / WS).

Opiniões e Sentenças Diversas. In: Humano demasiado Humano II. Trad. Paulo César de Souza. São Paulo: Companhia das Letras, 2008. (OS / VM).

RÉE, Paul. Psychologische Beobachtungen. In: Gesammelte Werke 1875-1885. Hrsg. Hubert Treiber. Berlin; New York: Walter de Gruyter, 2004. (OP / PB).

SCHOPENHAUER, Arthur. O mundo como vontade e como representação. Trad. Jair Barboza. São Paulo: Unesp, 2005.

Parerga e Paralipomena. Aforismos para a sabedoria de vida. Trad. Jair Barboza. São Paulo: Martins Fontes, 2002. 1995.

Sobre o fundamento da moral. Trad. Maria Lúcia Cacciola. São Paulo: Martins Fontes, 
Recebido: 05/02/16 Received: 02/05/16

Aprovado: 17/05/16

Approved: 05/17/16 